Supporting Information

\title{
Synthesis of Polylactide Nanocomposites Using $\alpha$-Zirconium Phosphate Nanosheets Supported Zinc Catalyst via in situ Polymerization
}

Yonghang Xu, a,b,c Limiao Lin, ${ }^{\mathrm{c}}$ Songshan Zeng, ${ }^{\mathrm{b}}$ Jingjing Liu, ${ }^{\mathrm{b}}$ Min Xiao, ${ }^{\mathrm{c}}$ Shuanjin Wang, ${ }^{c}$ Yuezhong Meng, ${ }^{\mathrm{c}, *}$ Luyi Sun ${ }^{\mathrm{b}, *}$

${ }^{a}$ School of Materials Science \& Energy Engineering, Foshan University, Foshan 528000, China

${ }^{b}$ Polymer Program, Institute of Materials Science and Department of Chemical \& Biomolecular Engineering, University of Connecticut, Storrs, Connecticut 06269,

USA

${ }^{c}$ The Key Laboratory of Low-carbon Chemistry \& Energy Conservation of Guangdong Province/State Key Laboratory of Optoelectronic Materials and Technologies, Sun Yat-sen University, Guangzhou 510275, China 


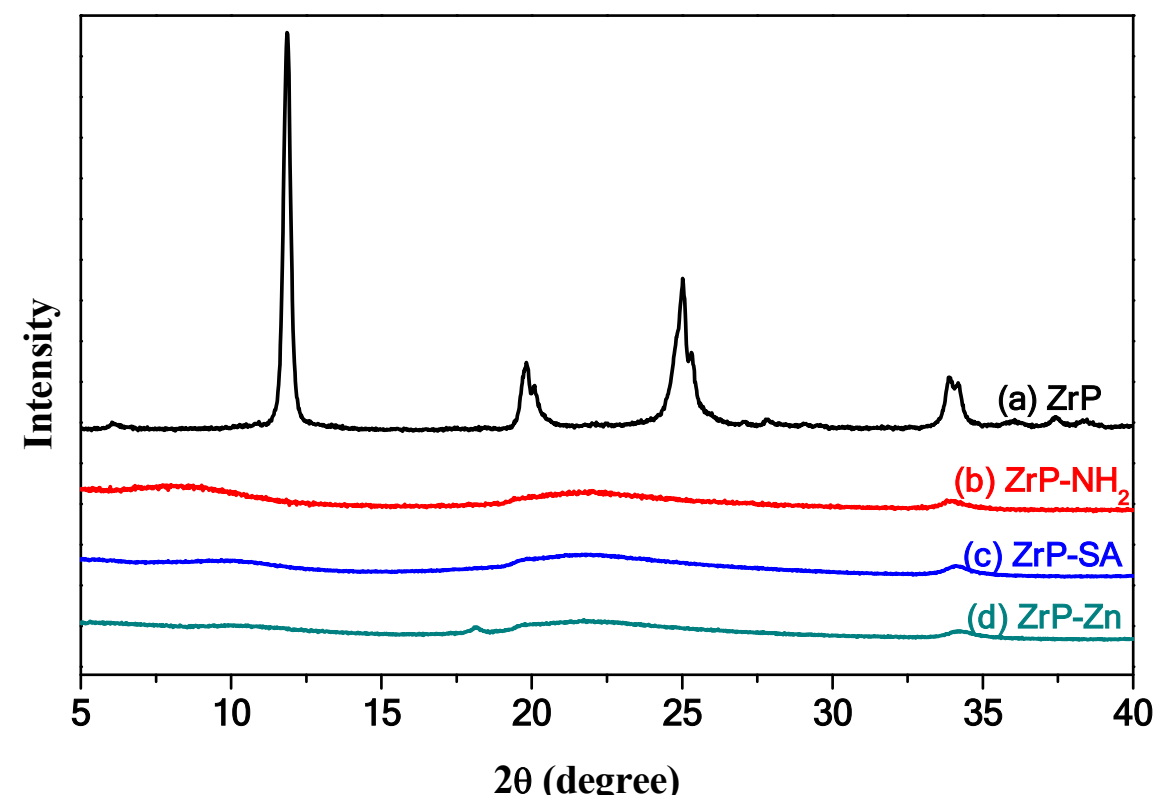

Figure S1. XRD patterns of $\mathrm{ZrP}, \mathrm{ZrP}^{-\mathrm{NH}_{2}}, \mathrm{ZrP}-\mathrm{SA}$, and $\mathrm{ZrP}-\mathrm{Zn}$.

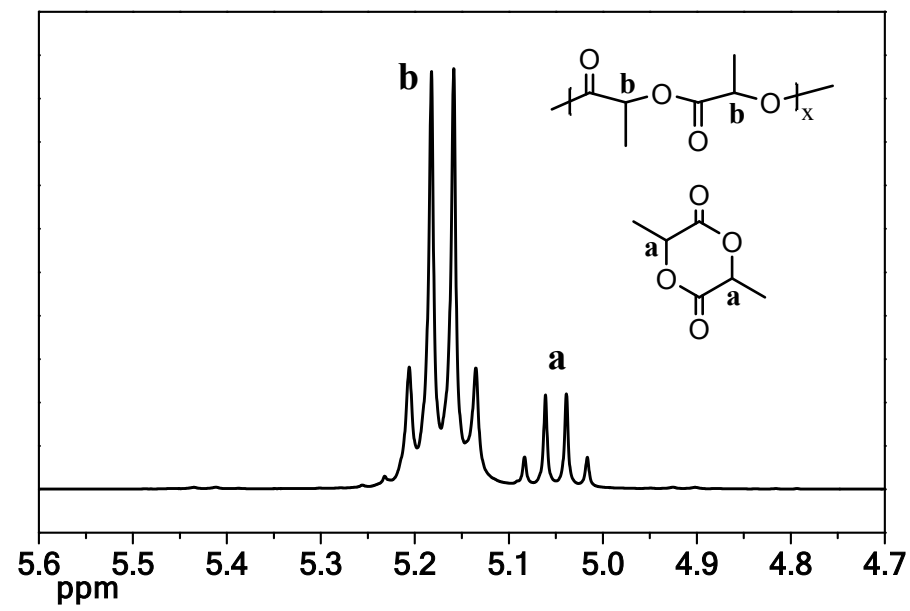

Figure S2. ${ }^{1} \mathrm{H}$ NMR spectrum of the PLA catalyzed by ZrP-Zn. Reaction condition: LA:catalyst $=100: 1$ (mass), $140{ }^{\circ} \mathrm{C}, 24 \mathrm{~h}$. 

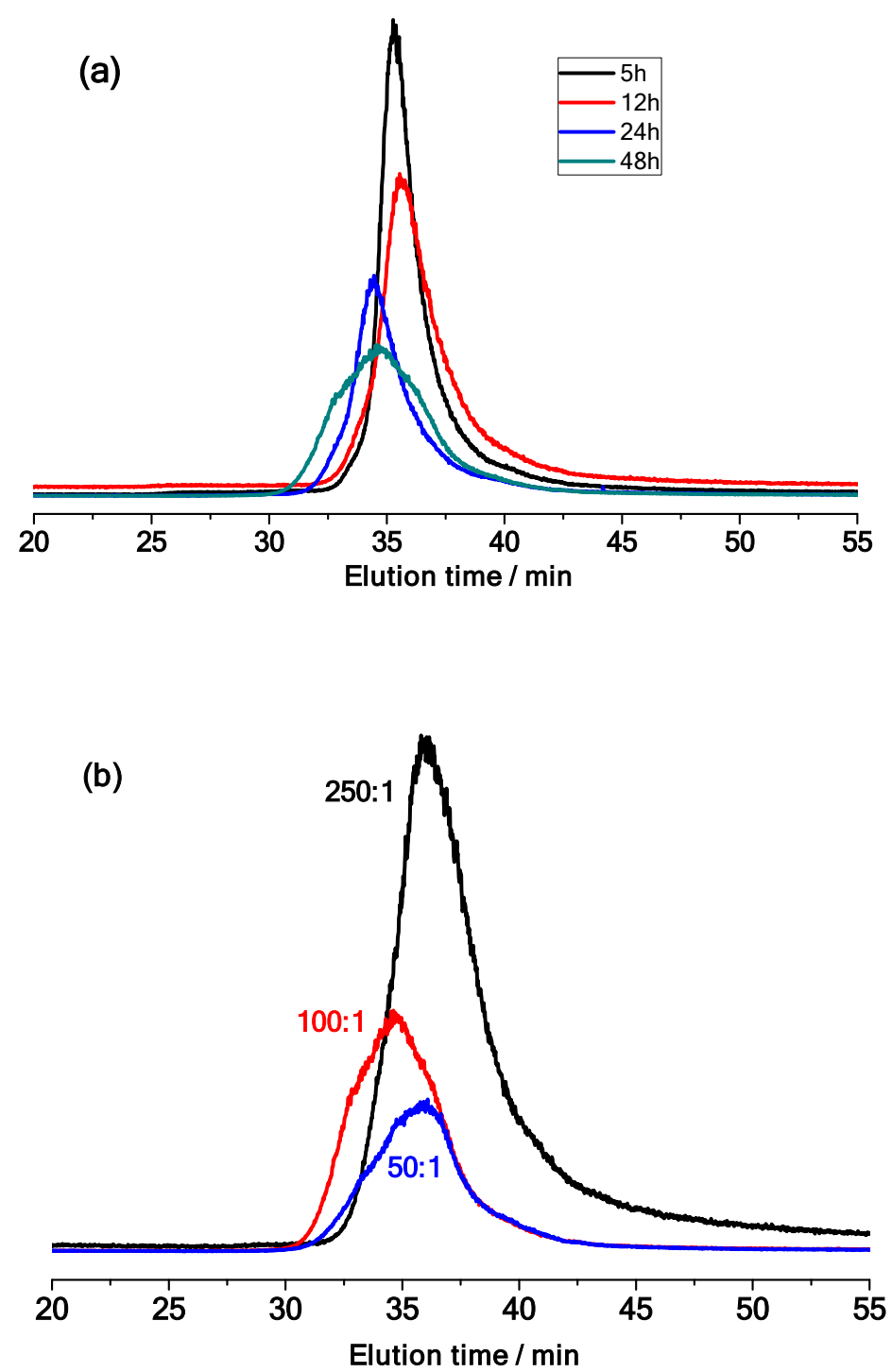

Figure S3. GPC curves of the PLA nanocomposites synthesized with varying (a) reaction time and (b) catalyst loadings. 

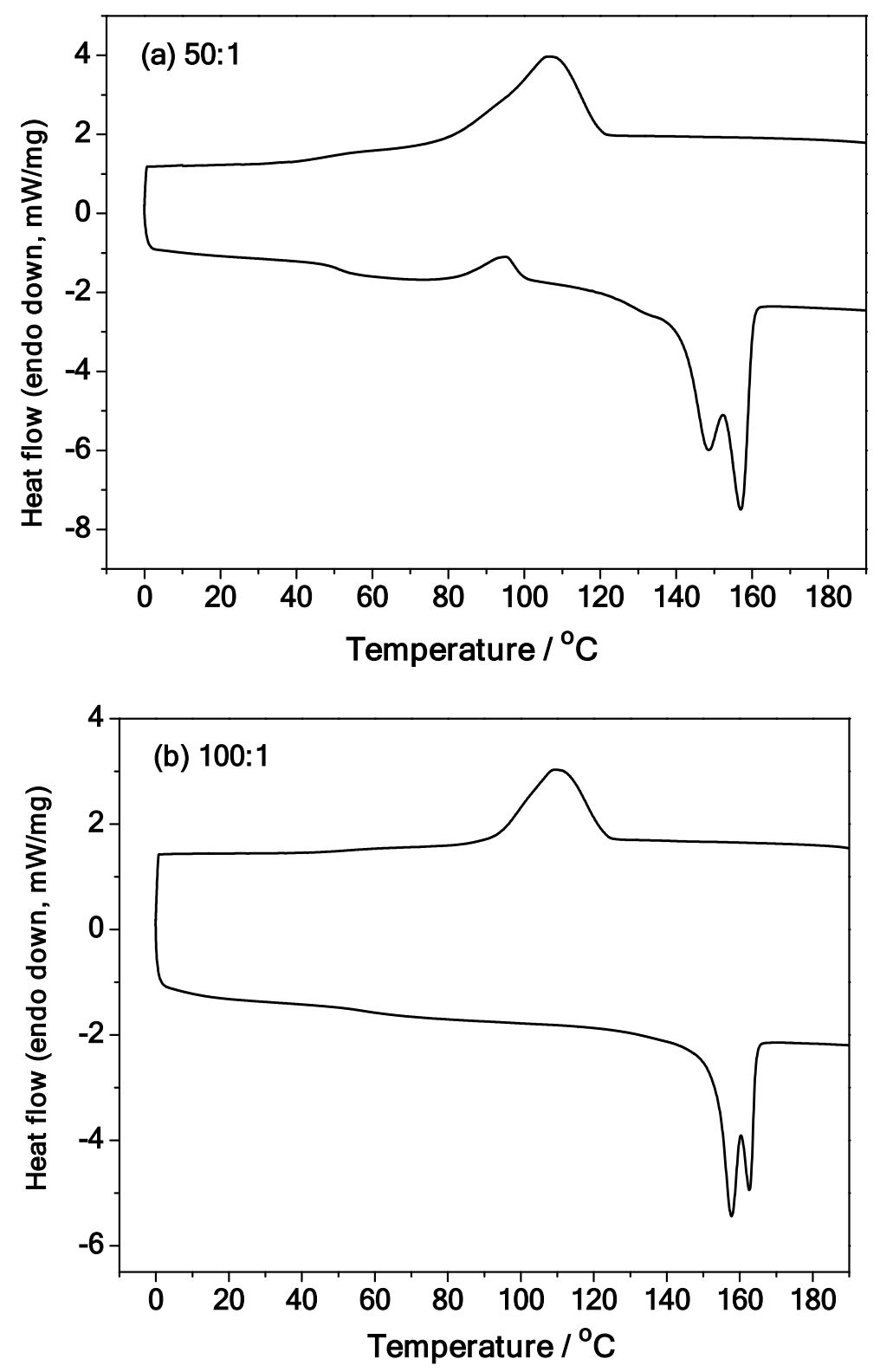

Figure S4. DSC thermograms of the PLA nanocomposites with a PLA/ZrP-Zn mass ratio of (a) 50 and (b) 100 . All cooling and heating runs were conducted at $10 \mathrm{~K} / \mathrm{min}$.

Table S1. Melting points and crystallinity of the PLA nanocomposites with various ZrP loadings. ${ }^{a}$

\begin{tabular}{ccccccc}
\hline Sample & $\begin{array}{c}\text { Mass ratio of } \\
\text { PLA/catalyst }\end{array}$ & $\begin{array}{c}M_{n} / \\
\mathrm{kg} / \mathrm{mol}\end{array}$ & $T_{m} /{ }^{\circ} \mathrm{C}$ & $\Delta H_{m} / \mathrm{J} / \mathrm{g}$ & $\Delta H_{c} / \mathrm{J} / \mathrm{g}$ & $X_{c} / \%$ \\
\hline $\mathrm{A}$ & 1000 & 18.0 & 163 & 56.3 & 36.9 & 21 \\
$\mathrm{~B}$ & 250 & 8.9 & 152 & 65.1 & -- & 69 \\
$\mathrm{C}$ & 100 & 9.6 & 163 & 53.6 & -- & 57 \\
$\mathrm{D}$ & 50 & 7.2 & 157 & 55.4 & 5.9 & 53 \\
\hline
\end{tabular}

${ }^{a}$ Determined from the second heating run $(10 \mathrm{~K} / \mathrm{min})$ of DSC thermograms. 